\title{
GPCRs Promote the Release of Zinc lons Mediated by nNOS/NO and the Redox Transducer RGSZ2 Protein
}

\author{
Pilar Sánchez-Blázquez, María Rodríguez-Muñoz, Concha Bailón, and Javier Garzón
}

\begin{abstract}
Aims: Morphine signaling via the $\mu$-opioid receptor (MOR) is coupled to redox-dependent zinc release from endogenous stores. Thus, MOR activation stimulates the complex formed by RGSZ2 (a regulator of G protein signaling) and neural nitric oxide synthase (nNOS) to produce NO, and to recruit PKC $\gamma$ and Raf-1 in a zincdependent manner. Accordingly, we investigated whether redox regulation of zinc metabolism was unique to the MOR, or if it is a signaling mechanism shared by G-protein coupled receptors (GPCRs). Results: A physical interaction with the RGSZ2-nNOS complex was detected for the following GPCRs: neuropeptides, MOR and $\delta$ opioid (DOR); biogenic amines, 5HT1A, 5HT2A, $\alpha 2 \mathrm{~A}$, D1 and D2; acetylcholine, muscarinic M2 and M4; excitatory amino acid glutamate, mGlu2 and mGlu5; and derivatives of arachidonic acid (anandamide), CB1. Agonist activation of these receptors induced the release of zinc ions from the RGSZ2 zinc finger via a nNOS/ NO-dependent mechanism, recruiting PKC $\gamma$ and Raf- 1 to the $C$ terminus or the third internal loop of the GPCR. Innovation: A series of GPCRs share an unexpected mechanistic feature, the $\mathrm{nNOS} / \mathrm{NO}$-dependent regulation of zinc ion signaling via a redox mechanism. The RGSZ2 protein emerges as a potential redox zinc switch that converts NO signals into zinc signals, thereby able to modulate the function of redox sensor proteins like PKC $\gamma$ or Raf-1. Conclusion: Redox mechanisms are crucial for the successful propagation of GPCR signals in neurons. Thus, dysfunctions of GPCR-regulated NO/zinc signaling may contribute to neurodegenerative and mood disorders such as Alzheimer's disease and depression.
\end{abstract}

Antioxid. Redox Signal. 00, 000-000.

\section{Introduction}

E MERGING EVIDENCE SUGGESTS an important role for zinc metabolism in cell signaling. This trace metal element is particularly abundant in the mammalian brain, with concentrations in the $\mu M$ range; yet resting free cytosolic zinc ions only reach concentrations in the $\mathrm{p} M$ to low $\mathrm{n} M$ range. With the appropriate regulation, transient increases in intracellular zinc ion concentrations can be produced that are immediately buffered to the aforementioned resting levels (4). This tight regulation of endogenous levels implicates zinc in redoxmediated cell signaling.

In neural tissue, nitric oxide synthase (nNOS) is primarily responsible for the production of nitric oxide (NO), which regulates a broad range of physiological functions. $\mathrm{NO}$ exerts most of action by reacting with cysteine $\mathrm{Zn} / \mathrm{S}$ sites in zinc finger proteins, promoting the release of zinc and the S-nitrosylation of these thiol groups $(32,49)$. The nitrosylation of cysteines is readily reversible, typically via the S-nitrosoglutathione reductase or thioredoxin systems $(31,49)$.

\section{Innovation}

In the adult nervous system, the production of $\mathrm{NO}$ and the eventual release of zinc ions is mainly mediated by nNOS activity, under the control of the glutamate NMDAR. Here, we describe a new feature shared by several GPCRs, whereby receptor activation is coupled to NO production and RGSZ2-mediated release of zinc ions. This GPCR-mediated process converts NO signals into zinc signals, altering the function of Redox sensor proteins such as PKC $\gamma$ and Raf-1. These findings may have important implications for understanding and treating neurodegenerative diseases and mood disorders, in which GPCRs and zinc metabolism are implicated.

While nNOS activation is typically linked to the NMDA glutamate receptor, the $\mathrm{G}$ protein-coupled $\mu$-opioid receptor (MOR) also stimulates NO production by regulating $\mathrm{nNOS}$ (47). The MOR is associated with nNOS through a series of regulatory proteins and, for example, the RGSZ2 protein

Cajal Institute, Consejo Superior de Investigaciones Científicas, Madrid, Spain. 
binds the PDZ binding motifs located in the N-terminal region of nNOS, thereby inhibiting NO production (14). RGSZ2 binding to the histidine triad nucleotide-binding protein 1 (HINT1) connects it to the MOR C-terminus $(1,18,43)$. Indeed, the MOR agonist, morphine, activates G $\alpha$ GTP subunits, some of which bind to the RGSZ2-nNOS complex and provoke transient production of NO $(43,47)$. One of the main physiological consequences of MOR-mediated NO production is the release of zinc ions from endogenous stores. Subsequently, these ions can bind to cysteine-rich regions in $\mathrm{PKC} \gamma$ and Raf-1, promoting their simultaneous recruitment to the HINT1 protein at the MOR $(45,46)$. The role of zinc signals as intracellular messengers is dependent on their temporal and spatial compartmentalization. Notably, rather than protecting $\mathrm{SH}$ groups from oxidation, the strong binding of zinc to sulfur in cysteine thiol groups increases the vulnerability of thiolates to oxidation (33). This results in redoxactive zinc/cysteine coordination environments that respond to mild physiological oxidation by releasing zinc ions, such as that produced by NO. By contrast, zinc-free cysteines remain unaffected and ready to capture free zinc ions (20). When coupled with the reversibility of zinc binding upon reduction of the oxidized sulfur, this property makes cysteine-coordinated zinc fingers efficient redox sensors (33). Binding of HINT1 and RGSZ2 to cytosolic regions of GPCRs is not restricted to the MOR; we have also detected this interaction in the cannabinoid CB1 receptor, as well as to a lesser extent in the $\delta$-opioid receptor (DOR) (10). As activation of the PLC/PKC and ERK1/2 pathways is shared by many GPCRs, we investigated whether regulation of nNOS and Redox release of endogenous zinc is a general feature of GPCR signaling in nervous tissue. Given the exquisite compartmentalization of nNOS regulation to the MOR's C terminus, we explored the possibility that the cysteine-rich domain (CRD) of the RGSZ2 N terminus could act as source of endogenous zinc ions released by GPCRactivated nNOS.

\section{Results}

\section{Activation of different GPCRs promotes the release of endogenous zinc ions via a mechanism involving $n N O S / N O$}

We sought to investigate whether the redox-induced mobilization of endogenous zinc was a signaling property shared by a range of neural GPCRs. First, we analyzed the capacity to mobilize zinc of agonists that act on GPCRs known to contain HINT1 at their corresponding $C$ termini, such as MOR, CB1R, and DOR (10). As reported previously (45), incubation of mouse brain slices with morphine increased Newport Green fluorescence (a measure of the zinc ions that are being released from endogenous stores), a MOR-mediated effect that was attenuated by the opioid antagonist naloxone. Likewise, the zinc-mobilizing effect of deltorphin II, a DOR agonist, was attenuated by its selective antagonist, naltrindole and similarly, the effect of the CB1R agonist, WIN 55-212-2, diminished following LY320135 administration, a specific antagonist of this receptor (Fig. 1). Taken together, these findings demonstrate that metabotropic GPCRs for endogenous opioid peptides (MOR and DOR) and for the arachidonic acid derivative anandamide (CB1R) are all capable of provoking the release of endogenous zinc ions.
We found that several neural receptors for biogenic amines (5HT1A and 5HT2A serotonin receptors, the $\alpha 2 \mathrm{~A}$ noradrenegic receptor, and D1 and D2 dopamine receptors) mediated the mobilization of zinc ions in response to agonist stimulation (Fig. 2). Dopamine receptor-mediated zinc mobilization was promoted by quinpirole, a specific D2 agonist, and by apomorphine, which acts on both D1R and D2R types. These effects were attenuated by GPCR antagonism, and they were also prevented by NOS/NO inhibition.

\section{The RGSZ2 protein is a redox sensor that releases zinc ions in response to NO}

The RGS17 protein, also known as RGSZ2, belongs to the Rz subfamily of RGS proteins $(21,30)$. Immediately upstream of the RGS domain, RGSZ2 contains a series of PDZ binding motifs that bind to the PDZ domain in nNOS (residues 61-64 MESI, 75-78 ADEV, and 76-79 DEVL). In the MOR, the RGSZ2-nNOS interaction serves to regulate NO production and the release of zinc from intracellular stores in response to morphine binding (14). Importantly for NO signaling, the amino terminus of RGSZ2 features a cysteine-rich domain (CRD: 28 to 40) that contains 9 cysteine residues out of a total of 13 .

To determine whether RGSZ2 CRD could bind zinc ions and release them in response to $\mathrm{NO}$ donors, the $\mathrm{N}$ terminal region on RGSZ2 (1-80) containing the CRD was exposed to the NO generators SNAP and NOR-3 $(100 \mu M)$, which released about two molar equivalents of zinc (Fig. 3A). A similar level of zinc release was observed in response to oxidation induced by $2.5 \mathrm{mM}$ hydrogen peroxide, a concentration that induces maximal release of zinc ions from PKC zinc fingers $(24,50)$, or by a combination of SNAP and $\mathrm{H}_{2} \mathrm{O}_{2}$. Phorbol-12myristate-13-acetate (PMA) produced no detectable release of zinc ions from the RGSZ2 CRD (Fig. 3B). Computational analysis revealed a linear arrangement of double zinc motifs in the RGSZ2 zinc finger [metal binding sites: http:// www.geneinfinity.org; DCPB: http://120.107.8.16/dbcp/ accessed on Jul 2, 2012; (34)]. The zinc-binding ligands in the RGSZ2 CRD are implicated in the tetrahedral coordination of each zinc atom with four cysteine ligands (S4), a structure termed the zinc ribbon (32). While the other members of the RGS-Rz subfamily can theoretically bind zinc via their CRDs, RGS19(GAIP) and RGS20(Z1), they could only accommodate one atom in a cysteine tetrahedral coordination (Fig. 3C).

\section{Impairment of RGSZ2 protein expression markedly attenuates GPCR-induced zinc release from endogenous stores}

The RGSZ2 protein appears to play an essential role in cellular homeostasis and, indeed, targeted deletion of its gene is lethal. Thus, the relevance of this protein was determined by reducing its expression in adult mice $(11,14)$. In brain slices from mice with impaired RGSZ2 expression, GPCR agonists induced the release of nondetectable to moderate levels of endogenous zinc (Fig. 4).

\section{GPCRs associate with RGSZ2 and HINT1 proteins in brain synaptosomes}

The association of the RGSZ2/nNOS signaling complex with the HINT1 protein at the MOR $C$ terminus appears 
FIG. 1. Signaling via the MOR, DOR, and CB1R is linked to zinc release via nNOS/NO activation. Coronal mouse brain slices were preloaded with $50 \mu \mathrm{M}$ cell-permeable Newport Green diacetate for $1 \mathrm{~h}$ and after its removal, the preparations were assayed. The evolution of spontaneous release of endogenous zinc was determined in Control (untreated) sections. For each receptor, consecutive sections were used to analyze the effect of the agonist alone or in combination with the antagonist or L-NNA. Fluorescent images were taken at various intervals using a $10 \times 0.4 \mathrm{HC}$ PL APO objective (excitation, 488; emission, 498-520) and the regions studied for each GPCR are indicated. The data at 30 and $60 \mathrm{~min}$ post-treatment are shown for baseline vehicle (Control), agonist $(3 \mu M)$ treated (A), agonist + antagonist $(10 \mu M)$ treated (Antagonist + A), and agonist + L-NNA $(10 \mu \mathrm{M})$ treated slices (L-NNA $+\mathrm{A})$. The following agonists and their antagonists were used: MOR, morphine (Merk) and naloxone (Tocris 0599); DOR, deltorphin II (Tocris 1180) and naltrindole (Tocris 0740); CB1R, Win55,212-2 (Tocris 1038), and LY320135 (Tocris 2387). Images were color indexed, and presented in gray and pseudocolor (no treatment), or pseudocolor only (for receptor studies). The numbers on the images indicate the luminosity corresponding to the red channel (indicative of fluorescence variation with respect to the control). Scale bar $=500$ $\mu \mathrm{m}$. The assay was typically repeated at least twice on brain coronal slices from different mice, with comparable results. Representative images are shown. (To see this illustration in color the reader is referred to the web version of this article at www.liebertpub.com/ars).

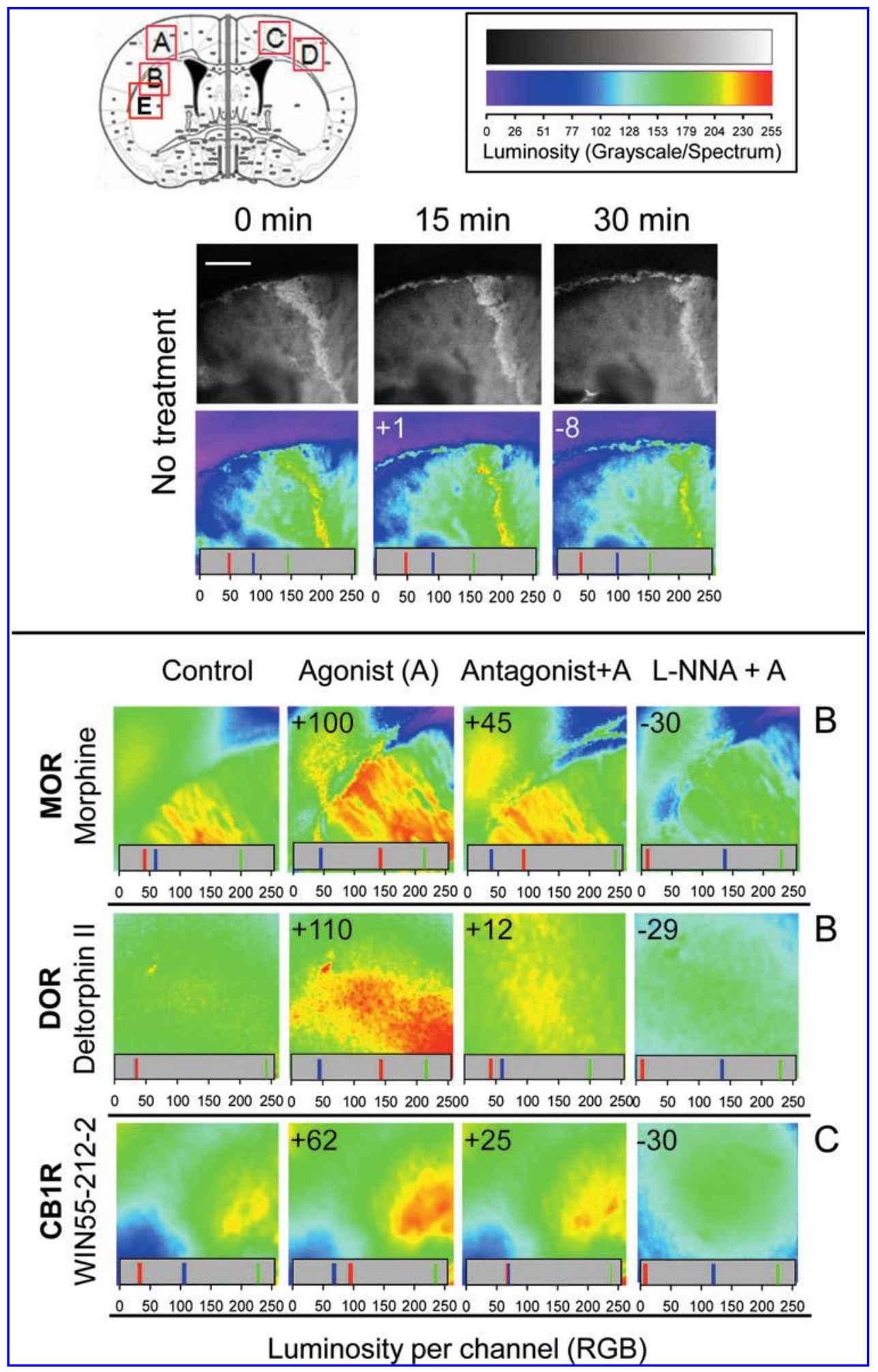

necessary for morphine to regulate the production of $\mathrm{NO}$ and the subsequent release of zinc from endogenous zinc finger proteins $(1,14,46)$. Therefore, we explored whether the GPCRs of interest were also associated with these proteins in brain synaptosomes. Antibodies recognizing external epitopes on the GPCRs were used to immunoprecipitate the corresponding receptor (Fig. 5A), thereby avoiding the blockage of their cytosolic sequences that may occur due to interaction with third partner proteins, such as $G$ proteins, RGS proteins, or others. The ex vivo assays revealed that all GPCRs studied co-precipitated RGSZ2, nNOS, and HINT1 proteins (Fig. 5B). This finding indicates that, in addition to regulating $\mathrm{G}$ proteins, GPCRs may also promote the activation of $\mathrm{nNOS} / \mathrm{NO}$ pathways. 


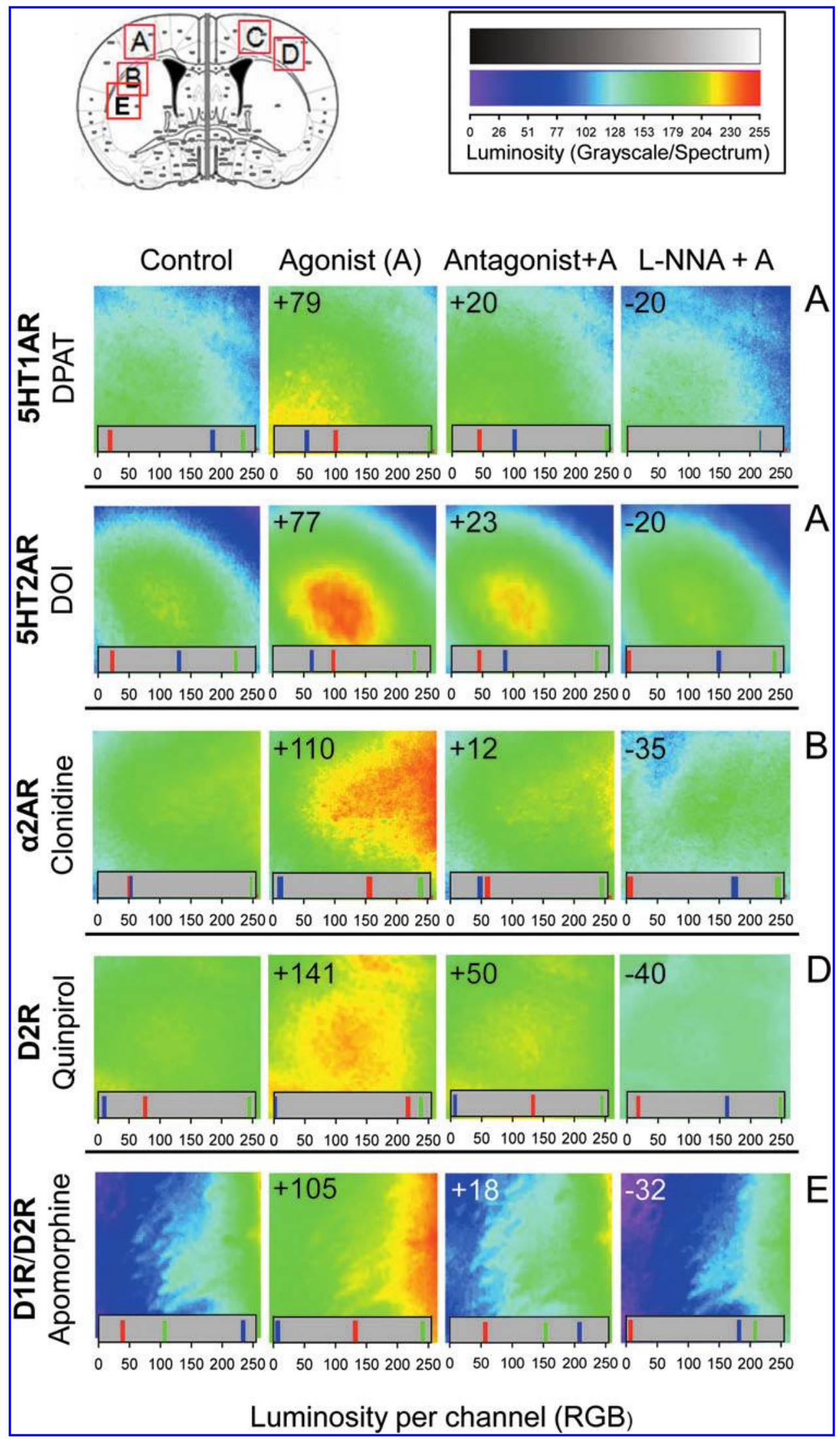

FIG. 2. Activation of 5HT1A and 5HT2A serotonin receptors, $\alpha 2 \mathrm{~A}$ adrenoceptors, and D1 and D2 dopamine receptors promotes the release of zinc ions via nNOS/NO. All details as in Figure 1. The following GPCR agonists and antagonists were used: 5HT1AR, 8H-DPAT (Tocris 1080) and NAN-190 (Tocris 0553); 5HT2AR, DOI (Tocris 2643) and AF 4PP (Tocris 0523); $\alpha 2 \mathrm{AR}$, clonidine (Tocris 0690) and yohimbine (Tocris 1127); D2R, quinpirole (Tocris 1061) and haloperidol (Tocris 0935); D1R/ D2R, apomorphine (Tocris 2073). (To see this illustration in color the reader is referred to the web version of this article at www.liebertpub.com/ars). 

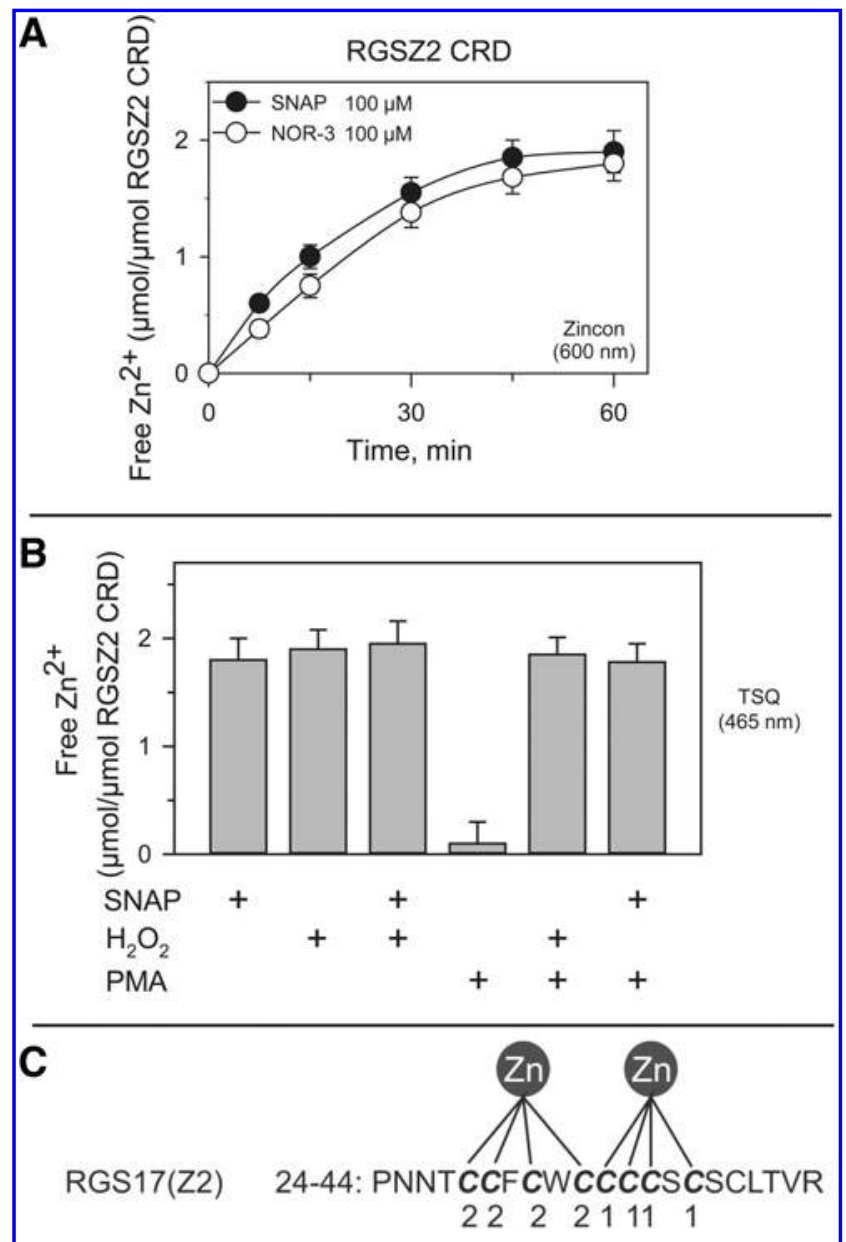

RGS19(GAIP) 35-55: SRNPCCLCWCCCCSCSWNQER $\begin{array}{llllll}2 & 2 & 2 & 1 & 1 & 1\end{array}$

\section{RGS20(Z1) 55-75: GSNACCFCWCCCCTCSCLTVR} $2 \quad 2 \quad 21111$

FIG. 3. The CRD of RGSZ2 protein is a zinc finger that coordinates the binding of two zinc atoms. (A) The cluster of cysteines in the $\mathrm{N}$ terminus region of RGSZ2 binds zinc and is redox sensitive. Time-dependent release of $\mathrm{Zn}^{2+}$ from RGSZ2 CRD was induced by maximal doses $(100 \mu M)$ of the NO donors SNAP or NOR-3. The $\mathrm{N}$ terminal region of RGSZ2 containing the CRD $(20 \mu M)$ was incubated with the NO donors $(100 \mu M)$ at RT. Zinc release was monitored at different intervals through its complexing with the zinc chelator Zincon and absorbance $(600 \mathrm{~nm})$ was recorded at RT on a BioChrom Ultrospec 2100 spectrophotometer (Cambridge, UK). The data represent the mean \pm SEM of three independent assays. (B) Release of $\mathrm{Zn}^{2+}$ from the RGSZ2 CRD induced by phorbol ester and peroxide. The RGSZ2 N terminal sequence containing the CRD was incubated with PMA $(1 \mathrm{~m} M)$, hydrogen peroxide $(2.5 \mathrm{mM})$, or SNAP $(100 \mu M)$. The bar histogram represents the mean \pm SEM of three independent experiments. (C) The CRD is present in N terminal sequences of the members of the RGS-Rz subfamily. Computational analysis of these proteins (34) revealed that the RGSZ2 zinc finger contains a linear arrangement of two zinc motifs capable of binding two zinc atoms (Metal detector: http://metaldetector.dsi.unifi.it/; DCPB: http://120.107.8.16/ dbcp/). The zinc-binding ligands in RGSZ2 CRD form a tetrahedral coordination for each zinc atom with four cysteine ligands (S4), a structure known as a zinc ribbon (32).
RGSZ2 physically interacts with the cytosolic $C$ terminus or the third internal loop of GPCRs

GPCRs exhibit notable differences in the length of the $\mathrm{C}$ terminus and third internal loop, regions that are essential for their interaction with signaling proteins and the regulation of their activities. When we studied the characteristics of these sequences for the GPCRs of interest (Fig. 5B), a short C terminal sequence was usually balanced by a long third internal loop and vice versa. Therefore, apart from the regulation of $\mathrm{G}$ proteins depending on the class of GPCR, cytosolic interactions probably occur via either the $C$ terminus or the third internal loop.

The MOR C terminus requires the HINT1 protein to recruit RGSZ2 (43), although RGSZ2 can also interact directly with other GPCRs. The formation of RGSZ2-GPCR complexes in vivo was supported by the results the bimolecular fluorescence complementation (BiFC) analysis (Fig. 6). Chinese hamster ovary $(\mathrm{CHO})$ cells were transfected with a mix of RGSZ2 coupled to VC155 (1:1) and the GPCR of interest coupled to the $\mathrm{C}$ terminus of VN173. The physical association of RGSZ2 with the GPCR allows the VC155 and VN173 fragments to form a stable fluorescent complex, which could be detected in several cells.

The participation of amino acid sequences of the $C$ terminal or the third internal loop in the GPCR-RGSZ2 interaction was determined by surface plasmon resonance analysis. The $\mathrm{C}$ terminal sequences of CB1 and 5HT2A, and the third internal loop sequences of $\alpha 2 \mathrm{~A}, \mathrm{M} 2, \mathrm{M} 4, \mathrm{D} 2$, and $5 \mathrm{HT} 1 \mathrm{~A}$, were covalently coupled to a CM5 sensor chip. Real-time interactions were studied by passing a solution containing the RGSZ2 protein over the sensor surface, and RGSZ2 was seen to interact directly with the $\mathrm{C}$ terminus or third cytosolic loop of these receptors. These findings demonstrate that RGSZ2 can be recruited to the GPCR environment either directly or through its binding to the HINT1 protein.

\section{Zinc supports the translocation of signaling proteins to the GPCR environment in vitro and ex vivo}

The interaction through which the RGSZ2 protein binds to the HINT1 protein was not affected by adding zinc to the medium. However, as purified recombinant zinc-binding proteins contain zinc, the RGSZ2-HINT1 interaction was also evaluated after experimental removal of this metal ion, which did not affect this association (Fig. 7A). Similarly, the binding observed between recombinant HINT1 and PKC $\gamma$ was not affected by exogenously added zinc, although HINT1-PKC $\gamma$ binding was clearly impaired after removing protein-bound zinc. In these circumstances, the addition of free zinc ions to the incubation media promoted a stronger interaction than that observed prior to zinc removal (Fig. 7A).

Besides the PKC $\gamma$ CRD, that of Raf- 1 also exhibits a zincdependent association with the MOR (45). Using membranes derived from mouse brain tissue, we determined the capacity of added zinc ions to promote the association of these signaling proteins with various GPCRs. The membranes were exposed for $4 \mathrm{~h}$ to increasing concentrations of zinc at $4^{\circ} \mathrm{C}$ before the GPCR was immunoprecipitated, and in the presence of low nM zinc, 5HT1A, 5HT2A, CB1, and D2 associated with Raf-1 and PKC $\gamma$ (Fig. 7B). Moreover, the NO donor SNAP enhanced the association of GPCRs with PKC $\gamma$ in these membrane preparations, although this interaction was 


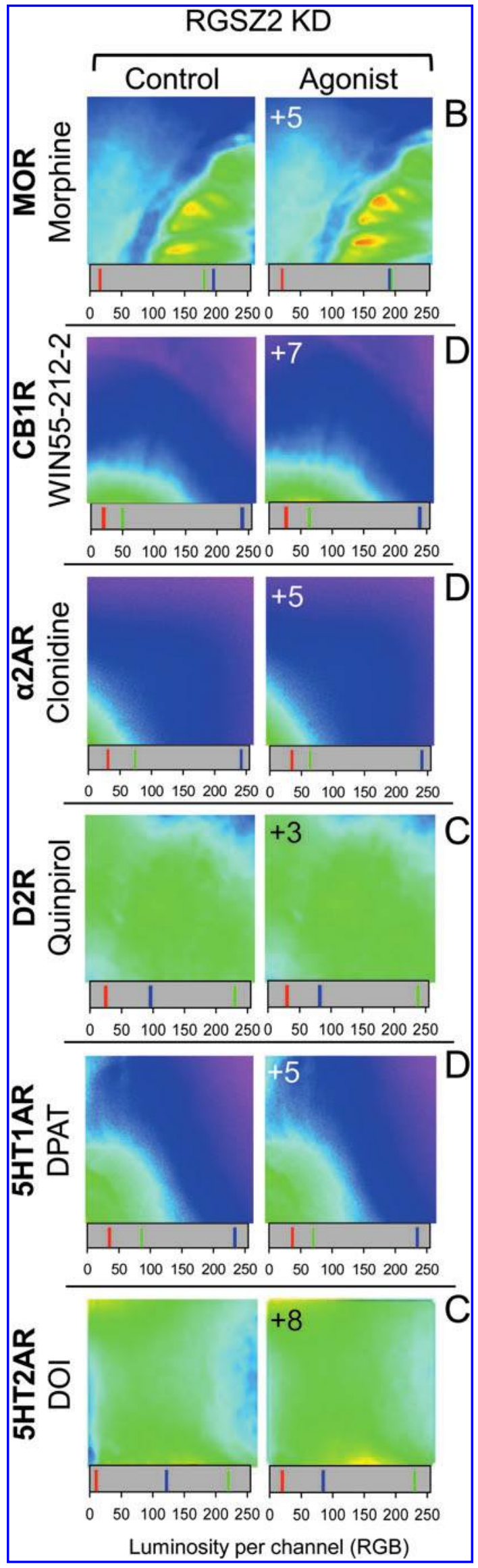

attenuated in the presence of the heavy-metal chelator, TPEN (Fig. 8A). Phorbol esters and calcium are cofactors that contribute to the activation of the conventional PKC isoforms. The binding of DAG or phorbol esters (PMA) to the regulatory domain of PKC causes the release of some of the associated zinc ions $(23,24,50)$, as well as promoting the release of PKC from the GPCR. In our membrane assays, we also observed that PMA diminished the association of PKC $\gamma$ with all the GPCRs evaluated (Fig. 8B). In vitro, PMA disrupted the association between recombinant HINT1 and PKC $\gamma$ proteins mediated by zinc, and promoted the activation of the PKC $\gamma$ released (Fig. 8C).

\section{Discussion}

In the present study, the regulation of $\mathrm{NO}$ production and the subsequent release of zinc ions from intracellular stores by neuronal GPCRs have been described. In the light of this data, the RGSZ2 protein emerges as a potential redox transducer that can be regulated by a variety of GPCRs. Zinc ions released from the RGSZ2 zinc finger domain by the action of NO can facilitate the coupling of redox sensor proteins such as PKC $\gamma$ or Raf- 1 to the $C$ terminal or third internal loop of these metabotropic receptors. Thus, redox signaling represents a process used commonly by the most abundant subfamily of cell surface receptors, mobilizing zinc ions from intracellular stores to successfully integrate their signals into adaptive neuronal processes.

The GPCRs analyzed all associate with the RGSZ2 zinc finger protein and with the HINT1 protein, which recruits a series of regulatory proteins to the GPCR's environment in a $\mathrm{NO}$ and zinc-dependent manner, including PKC $\gamma$ and Raf-1. The RGSZ2 and HINT1 proteins are widely distributed throughout the CNS $(11,28,30)$, and they co-localize with GPCRs in the cell membrane where they contribute to the propagation of extracellular signals (15). The GPCR-mediated activation of PKC $\gamma$ and ERK1/2 kinases is part of the negative regulation of certain GPCRs, such as the MOR and CB1R (9, 13). Thus, NO signaling participates in GPCR desensitization, although it is also required for the GRK- and $\beta$-arrestindependent internalization of these receptors. The agonistinduced production of NO separates $\beta$-arrestin from NOS binding and it targets the released $\beta$-arrestin to clathrin, initiating internalization of the GRK-phosphorylated GPCR (41). These are just a few examples of the relevance of redox processes and zinc mobilization in GPCR-mediated neuronal signaling.

The link between the glutamate NMDAR, NO production, and nitrosative signaling has been well documented. Thus, in postsynaptic neuron nNOS binds to PDZ binding motifs in the PSD-95 scaffold protein via its $\mathrm{N}$ terminal PDZ domain.

FIG. 4. The RGSZ2 protein is required for NO-mediated release of endogenous zinc in response to GPCR activation. The zinc-releasing activity of different GPCR agonists was analyzed in coronal slices obtained from control mice and mice with defective RGSZ2 expression. Antisense oligodeoxynucleotides for RGSZ2 mRNA effectively reduced the expression of the protein $(11,14)$. The agonists indicated were administered at $10 \mu \mathrm{M}$ and the fluorescent data were obtained $60 \mathrm{~min}$ post-agonist treatment. All details as in Figures 1 and 2. (To see this illustration in color the reader is referred to the web version of this article at www.liebertpub.com/ars). 
FIG. 5. A series of GPCRs associate with RGSZ2 and HINT1 proteins in brain synaptosomal membranes. (A) Antibodies (affinity-purified IgGs) directed against extracellular domains of the GPCRs of interest. (B) Solubilized synaptosomes from mouse cerebral cortex were incubated with the described biotinylated anti GPCR antibodies. After recovery with streptavidin-sepharose, the GPCR-containing complexes were processed to remove the IgG before immunodetection of the GPCR and associated proteins (see Materials and Methods). Immunodetection of the GPCR and coprecipitated nNOS, RGSZ2, and HINT1 proteins: For each GPCR, the organization of cytosolic third loop and $\mathrm{C}$ terminus is indicated. The dividing line indicates that RGSZ2 and HINT1 immunodetection for CB1R and $\alpha 2 \mathrm{AR}$ was performed in a separate blot.

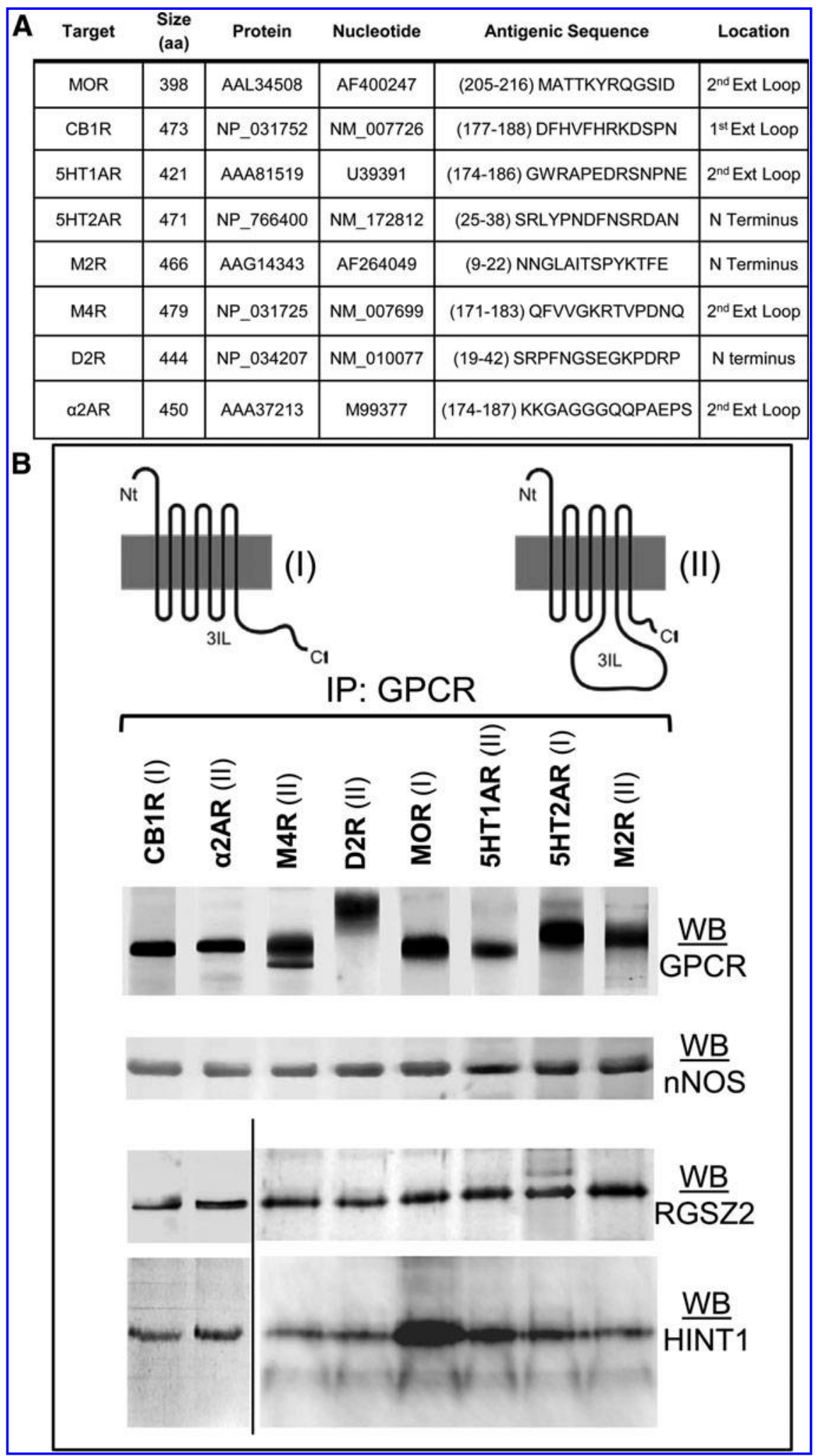

NMDAR activation then leads to calcium permeation and the formation of intracellular calcium-calmodulin complexes that activate nNOS to produce NO, as well as producing other effects. NMDAR signaling is propagated by NO-mediated Snitrosylation of the cysteine residues of many proteins, such as N-ethylmaleimide sensitive factor and stargazing, which directly regulate the function of the AMPAR, and that of the NMDAR indirectly (49). The mechanisms underlying GPCRinduced $\mathrm{NO} /$ zinc signaling have principally been analyzed for the MOR, identifying the fundamental role of HINT1. The HINT1 protein is a member of the HIT family of proteins that display conserved sequence identity in a broad range of 


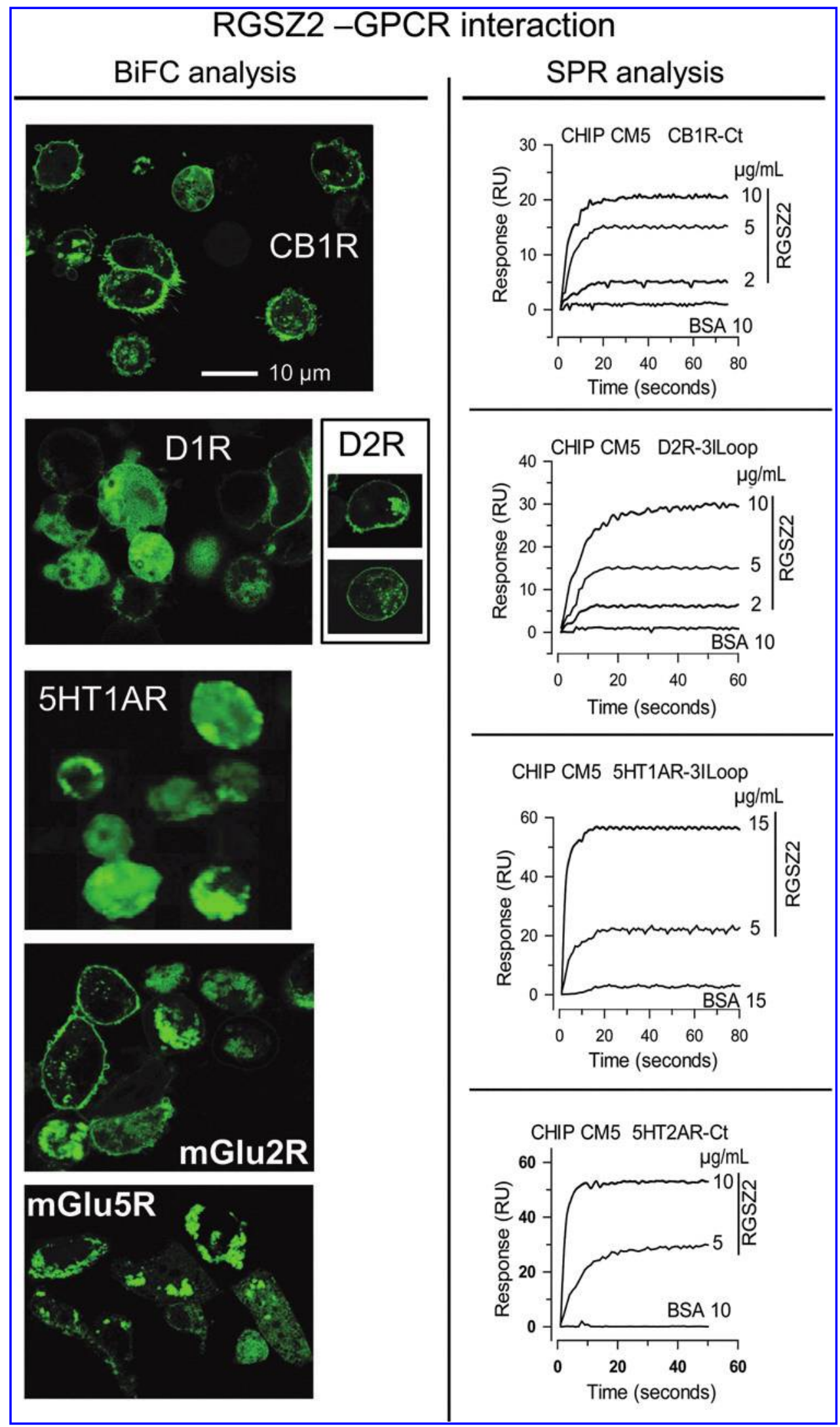

FIG. 6. Physical association of GPCR cytosolic regions with RGSZ2 protein. BiFC analysis: RGSZ2 interaction with GPCRs. CHO cells were transiently co-transfected with cDNAs encoding RGSZ2 ${ }^{\mathrm{VC} 155}$ and the corresponding $\mathrm{GPCR}^{\mathrm{VN173}}(0.8 \mu \mathrm{g})$. Fluorescent signals were only obtained after the direct physical association of both proteins, which allows VC155 and VN173 to correctly assemble the active fluorescent molecule. Fluorescent images showing positive cells in the observed field are shown. SPR analysis: The cytosolic third loop or N terminal region of the GPCR under study was covalently anchored to a CM5 chip and RGSZ2 protein added in the fluid phase. Binding of RGSZ2 to the GPCR amino acid sequence was detected through the increase in resonance units (RU). BSA was used as a negative control. (To see this illustration in color the reader is referred to the web version of this article at www.liebertpub.com/ars). 
organisms including mycoplasma, plants, and humans. HINT1 exists as a homodimer that specifically binds zinc ions without affecting its tertiary structure $(25,43)$, suggesting that zinc participates in HINT1's interaction with third party proteins. Interestingly, HINT1 was initially named as a PKC inhibitory (PKCi) protein, as it binds to the regulatory domain of conventional PKC isoforms and stabilizes this kinase in its inactive form $(25,35)$. Like the PSD-95, the RGSZ2 protein contains PDZ binding motifs that recruit nNOS, and these RGSZ2-nNOS complexes couple to the cytosolic $\mathrm{C}$ terminus of the MOR via the HINT1 protein $(1,14,18,43)$. The interaction of HINT1 with RGSZ2 does not require zinc ions, although binding of PKC $\gamma$ to the HINT1 protein is clearly dependent on this metal ion. The binding of zinc ions to the $\mathrm{PKC} \gamma \mathrm{C} 1$ regulatory domain promotes its folding into the

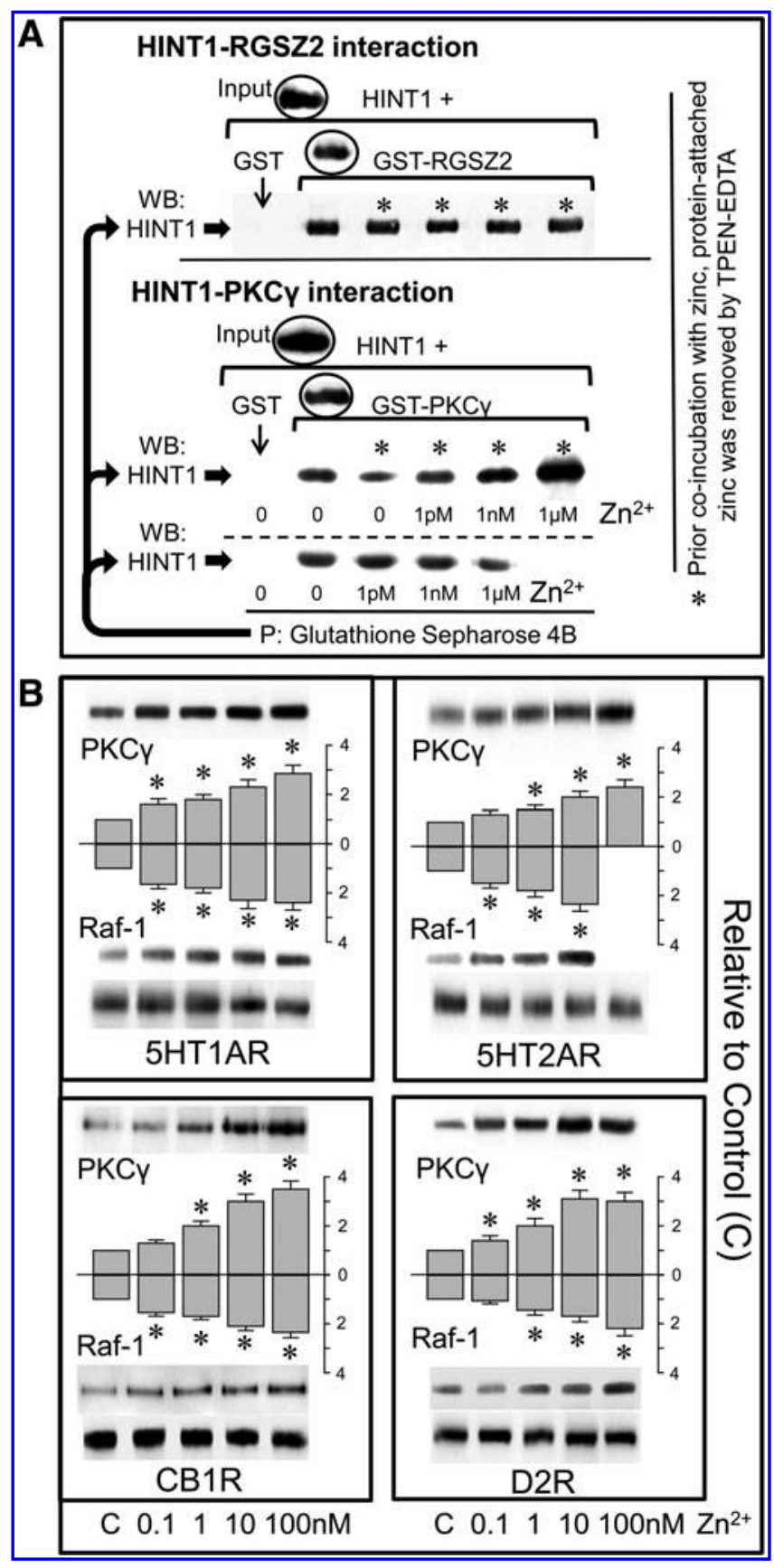

inactive conformation of the kinase (50) that can interact with the HINT1 protein. Accordingly, zinc-depleted PKC $\gamma$ displays poor affinity for the HINT1 protein, while this interaction was strongly enhanced in the presence of zinc ions. This observation indicates that zinc also participates in this intermolecular interaction probably trough is simultaneous binding to HINT1 histidines and PKC $\gamma$ zinc finger cysteines.

Thus, a series of concurrent processes position the inactive PKC $\gamma$ in the MOR environment where its activation can be tightly regulated to prevent the unwanted spreading of its effects. In this domain, MOR-activated PLC $\beta$ provides DAG to activate the HINT1-bound PKC $\gamma$. By interacting with the histidines of the PKC regulatory domain, this DAG lipid signal releases part of the zinc content and unfolds the kinase into its active conformation $(23,24,50)$. Moreover, by acting on HINT1 histidines, DAG would also provoke the release of the zinc ions required to support PKC $\gamma$-HINT1 inhibitory association. This action weakens the intermolecular bridging and disorders the surface of $\mathrm{PKC} \gamma$ involved in its binding to HINT1, favoring the release of the active kinase. Similarly, MOR-released zinc ions also promote the binding of inactive Raf- 1 to the HINT1 protein, facilitating PKC $\gamma$-mediated activation of the Raf-1-ERK1/2 pathway (45). PKC can also be activated by reactive oxygen species (ROS); however, ROS do not enhance the activation promoted by cofactors such as DAG and calcium but rather, they fix the kinase in a persistent, autonomously active form $(19,22)$. Significantly, NADPH oxidase/ROS production and the sustained activation of PKC $\gamma$ triggered by opioids are essential to develop and maintain NMDAR-mediated tolerance to the analgesic effects of morphine $(8,44)$. Thus, the action of PKC $\gamma$ on NADPH oxidase subunits promotes the production of ROS (3), which remove the DAG-resistant zinc from the regulatory domain of $\mathrm{PKC} \gamma$ and fix the kinase in its active form (22).

The concept of a biological redox switch, or more specifically, redox zinc switch, involves motifs in peptides or proteins that utilize the redox chemistry of cysteine thiol groups to bind and release zinc ions $(32,39)$. Controlling the

FIG. 7. In vitro association between RGSZ2/PKC $\gamma$ and HINT1, and $e x$ vivo association between PKC $\gamma /$ Raf1 and different GPCRs: the effect of zinc ions. (A) The HINT1 protomer was used at $200 \mathrm{nM}$, whereas GST-RGSZ2 and GST-PKC $\gamma$ were used at $100 \mathrm{nM}$. GST alone did not bind to the HINT1 protein (negative control). The interaction of the signaling proteins was studied before and after zinc was removed from the recombinant proteins (TPEN-EDTA buffer). After the removal of zinc, the influence of increasing concentrations of zinc on these interactions was studied. Glutathione sepharose $4 \mathrm{~B}$ was added to capture the GST fusion protein and the associated HINT1 protein. The proteins were then resolved by SDS-PAGE chromatography and the presence of HINT1 was analyzed in Western blots. (B) Brain synaptosomes were incubated with zinc chloride for $4 \mathrm{~h}$ at $4^{\circ} \mathrm{C}$. Free zinc was removed by three cycles of centrifugation and washing. Next, GPCRs were immunoprecipitated, and the associated PKC $\gamma$ and Raf1 were detected using appropriate antibodies. The study was repeated at least twice using different preparations from cortical synaptosomes. Data are expressed as the mean \pm SEM with respect to the control (no zinc, arbitrary value of 1 ). Equal loading was determined from the GPCR signal. *Significant difference with respect to the control group, $p<0.05$. 


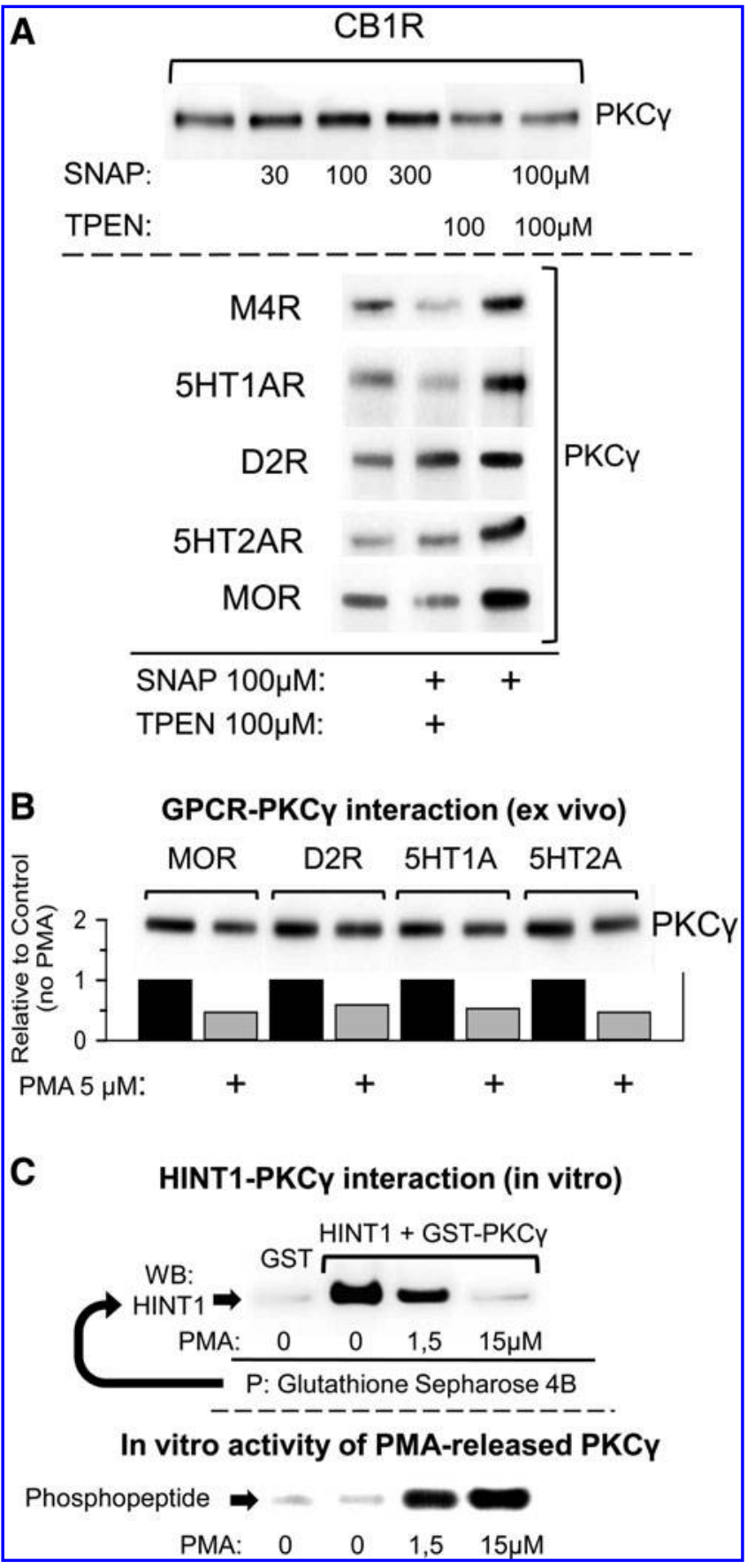

FIG. 8. NO provides the zinc ions required for PKC $\gamma$ to associate with GPCRs: the effect of PMA on NO/zincinduced PKC $\gamma$ recruitment to GPCRs. (A) Synaptosomal membranes derived from mouse cerebral cortex were incubated with the NO donor SNAP $(30 \mu M, 100 \mu M$, and $300 \mu \mathrm{M})$ in the presence or absence of the heavy-metal ion chelator TPEN $(100 \mu M)$, and the effects on the association of PKC $\gamma$ with the different GPCRs were evaluated. (B) Incubation of synaptosomal membranes with phorbol-12myristate-13-acetate (PMA, $5 \mu \mathrm{M}$ ) diminished the association of GPCRs with PKC $\gamma$. The GPCRs served as a loading control. (C) The association of zinc-free PKC $\gamma$ and HINT1 was promoted by the presence of $1 \mu \mathrm{M}$ zinc chloride. After removal of the free zinc ions, the effect of PMA on the HINT1$\mathrm{PKC} \gamma$ association was evaluated, as was the activity of the kinase. availability of zinc and the cysteine ligand-based redox reactions is essential to modulate certain transient heterologous protein-protein interactions (quinary structure) (32). Lipid second messengers such as DAG, as well as redox action and zinc ions, dynamically regulate PKC activity by switching the kinase between its unfolded active and folded inactive state, the latter binding more readily to the HINT1 protein at the GPCRs. Both activating agents, lipid second messengers and ROS, release zinc ions from $\operatorname{PKC}(22,50)$ and within a given kinase activation cycle, zinc must remain in close proximity to facilitate the recovery of the kinase for the next cycle (23). These requirements, coupled with the compartmentalization of GPCR redox signaling, suggest that the NO-sensitive source of zinc ions should be incorporated into this regulatory machinery. As RGSZ2 exerts an inhibitory influence on NO production, which is lifted upon MOR activation (14,47), our results indicate that the regulation of the zinc finger of RGSZ2 by mild oxidation of nNOS/NO could be coupled to PKC, providing the kinase with the zinc ions necessary for it to reach its inactive state and bind to the HINT1 protein in the surroundings of the GPCR (Fig. 9). The release of zinc ions appears not to compromise other functions of RGSZ2 and thus, the RGSZ2 redox zinc switch would appear to act as a redox transducer (32) that releases zinc ("zinc signal"), which can in turn modulate the activity of PKC $\gamma$ and Raf- 1 , among other targets. By contrast, PKC behaves as a redox sensor, whereby the ROS-induced release of zinc ions alters its activity (kinase activation).

The excess generation of NO and NO-derived reactive nitrogen species leads to nitrosative stress and altered cell metal ion metabolism, both of which have been implicated in the pathophysiology of neural disorders $(17,37)$. Typically, NMDAR overactivation at least partially contributes to neurological diseases such as Alzheimer's and Parkinson's diseases, multiple sclerosis, and amyotrophic lateral sclerosis (27), as well as mood disorders such as schizophrenia and depression $(29,36)$. Nonetheless, the link between GPCR signaling, NO production, and zinc metabolism raises the possible role of metabotropic receptors in certain neural disorders. The GPCR-associated and nNOS-coupled RGSZ2 protein is implicated in human cognitive ability, while the genome wide association database links this gene to Alzheimer's disease, narcolepsy, and panic disorder (https:// gwas.lifesciencedb.jp/cgi-bin/gwasdb/gwas_gene.cgi?name= RGS17 accessed on Jul 2, 2012). Moreover, where the RGSZ2 gene resides, locus $6 \mathrm{q} 25$, is one of the most relevant loci for schizophrenia-susceptibility on this chromosome (26). Impaired RGSZ2 expression also induces overstimulation of the nNOS/NO pathway, as well as rapid and durable loss of GPCR function (14). The HINT1 protein has also been implicated in certain mental disorders, including schizophrenia and bipolar disorder (2). A disruption in zinc homeostasis is increasingly associated with the pathophysiology of affective disorders and interestingly, depression has been correlated with serum hypozincemia. Indeed, zinc exhibits antidepressant-like activity in preclinical animal models. Moreover, the efficacy of antidepressants that block serotonin reuptake and normalize serum zinc levels suggests that this effect is mediated by GPCRs $(5,38)$. Dysfunction of aminergic receptors, such as 5HT1A and 5HT2A, is typically implicated in depression. Thus, impaired coupling of these serotonin receptors to redox signaling (e.g., nNOS regulation and $\mathrm{NO}$-dependent 
release of zinc ions) may diminish their signaling capacity. In such cases, the strength of the zinc signals produced by these GPCRs can be improved by increasing agonist input, as occurs when serotonin reuptake is inhibited by antidepressants. Given the implication of zinc homeostasis in brain disorders, several

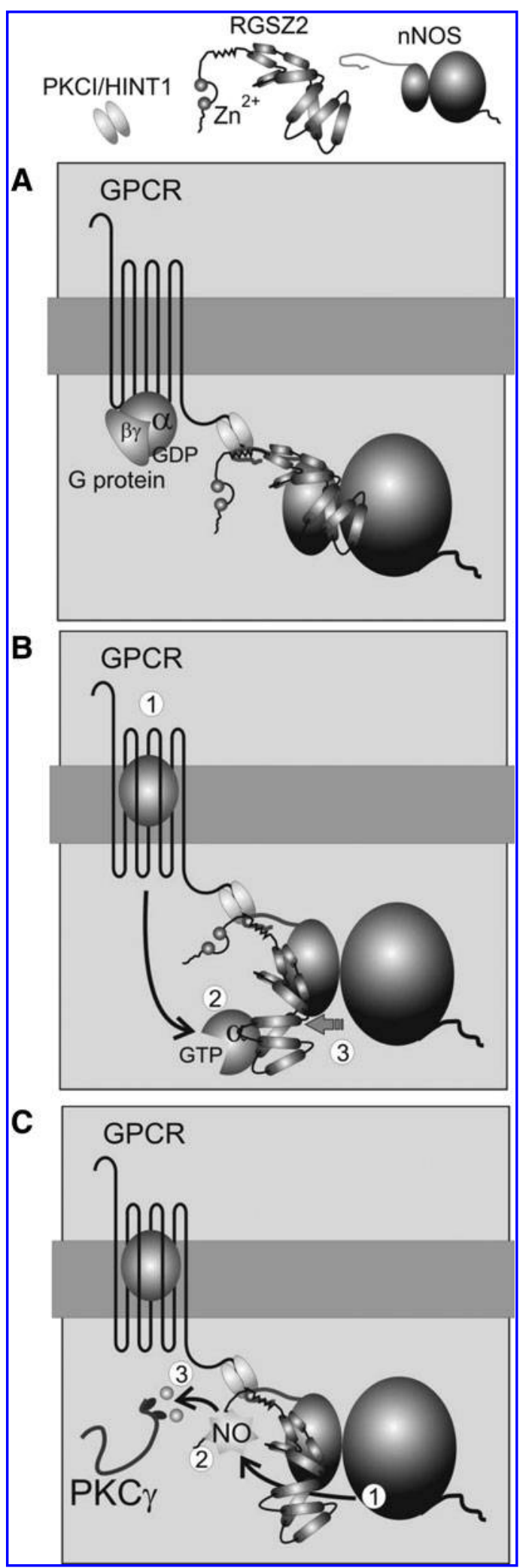

therapies based on metal ion chelation, redistribution and supplementation are currently in development (16).

In summary, we found that a range of neuronal GPCRs that respond to endogenous ligands of diverse chemical nature all physically couple with the RGSZ2-nNOS signaling complex. Activation of these receptors increases NO production and releases zinc ions from redox zinc switches, such as the RGSZ2 protein. These findings demonstrate that GPCR signaling depends on redox processes and zinc mobilization for successful integration into neuronal metabolism.

\section{Materials and Methods}

\section{Zinc microfluorescence imaging in CD1 mouse striatal slices}

To image intracellular $\mathrm{Zn}^{2+}$, brain slices (200 $\mu \mathrm{m}$ thick) were preloaded for $1 \mathrm{~h}$ with $50 \mu \mathrm{M}$ of cell-permeable Newport Green DCF diacetate (N7991, Invitrogen), $0.1 \%$ pluronic acid (P3000MP, Invitrogen), and 0.5\% dimethyl sulfoxide, as described previously (45). Saline, agonists, and antagonists were added to the wells, and the contribution of NO to zinc signals was determined using the NOS inhibitor NG-nitro-Larginine (L-NNA). Images were obtained by confocal microscopy on a Leica DMIII 6000 CS confocal fluorescence microscope equipped with a TCS SP5 scanning laser (excitation, $488 \mathrm{~nm}$; emission, $498-520 \mathrm{~nm}$ ) and using a $10 \times 0.4 \mathrm{HC}$ PL APO objective. See also Supplementary Materials and Methods (Supplementary data are available online at www.liebertonline/ars).

\section{In vitro determination of zinc release from rRGSZ2}

Free zinc ions were detected as described previously (45). The N-terminal $(\mathrm{Nt})$ region of RGSZ2 was obtained as a GST fusion protein and this RGSZ2 Nt protein was incubated for 30 min at RT with $100 \mu \mathrm{M} \mathrm{ZnCl}_{2}$. Free zinc was removed by extensive washing and centrifugation in an Amicon Ultra-4 centrifugal filter device (UCF8 01024), followed by buffer exchange in PD-10 gel chromatography columns (GE

FIG. 9. Scheme describing the regulation of NO production by GPCRs and the release of zinc ions from the RGSZ2 zinc finger. (A) The $C$ terminus or third internal loop of the GPCR binds directly to the RGSZ2-nNOS signaling complex, which may also associate with the GPCR indirectly via the HINT1 protein. (B) Agonist binding activates G $\alpha \mathrm{GTP}$ subunits [1], some of which bind to the RGS domain in the RGSZ2 protein [2]. This action releases the inhibition of nNOS activity by RGSZ2 [3], (C) resulting in the production of $\mathrm{NO}$ [2], which in turn releases zinc ions from the cysteine residues of the RGSZ2 zinc finger [2]. PKC is a zinc-binding protein (40), and these ions stabilize the inactive folded form of the kinase that binds to the GPCR-coupled HINT1 protein. Zinc binding to the $P K C \gamma$ regulatory domain also increases its affinity for cofactors such as DAG [3]. DAG produced by PLC $\beta$ releases PKC $\gamma$ from its inhibitory association with the HINT1 protein, also releasing part of the PKC $\gamma$-associated zinc and thereby promoting the unfolding of the kinase to an active conformation (24). The ROS produced by NADPH oxidase releases the DAG-resistant zinc from the PKC $\gamma$ CDR and fixes the kinase in a persistent active form $(22,50)$. After DAG is released, PKC activity diminishes, and it requires zinc to again bind to DAG $(6,7)$. Thus, a new PKC recruitment/activation cycle can start at the GPCR. 
Healthcare 17-0851-91). GST-RGSZ2 Nt was concentrated $(20 \mu \mathrm{M})$ and then exposed at the intervals indicated to $100 \mu \mathrm{M}$ of the NO donors SNAP and NOR-3, or to $2.5 \mathrm{mM}$ hydrogen peroxide (all in HEPES buffer; $25 \mathrm{mM}$, pH 7.8). Complexing was initiated by adding the zinc chelator Zincon $(40 \mu \mathrm{M}$; Sigma \#96440) and the optical density was read at $600 \mathrm{~nm}$. Another set of assays was performed by adding TSQ to the protein samples at a final concentration of $10 \mu \mathrm{M}$. The RGSZ2 $\mathrm{Nt}$-containing samples were excited at $334 \mathrm{~nm}$ and fluorescence emission was recorded at $465 \mathrm{~nm}$ in a spectrofluorimeter. A standard zinc solution (Sigma 39059) was used to calibrate the assay systems.

\section{Preparation and solubilization of the synaptoneurosome-enriched fraction: GPCR immunoprecipitation and co-precipitation of associated proteins}

All procedures involving mice were performed in strict accordance with the guidelines of the European Community for the Care and Use of Laboratory Animals (Council Directive 86/609/EEC), and Spanish Law regulating animal research (RD 1201/2005). The experimental protocols were reviewed and approved by the Committee for Animal Experimentation at the CSIC.

For the immunoprecipitation studies, the cerebral cortex from 8 CD1 mice (Charles River, Spain) were pooled, and the assays were repeated at least twice with samples obtained from different mice. The methods used to prepare the PAG synaptosomal fraction have been described previously (46). The affinity-purified IgGs against the extracellular domains of GPCRs were labeled with biotin (Pierce 21217 and 21339), and immunoprecipitated from solubilized membranes as described $(12,42)$. The immunoprecipitated proteins were resolved by SDS/polyacrylamide gel electrophoresis (PAGE) in $10 \mathrm{~cm} \times 10 \mathrm{~cm} \times 1.5 \mathrm{~mm}$ gel slabs $(7 \%-14 \%$ total acrylamide concentration, $2.6 \%$ bisacrylamide cross-linker concentration), and the separated proteins were then transferred to $0.2 \mu \mathrm{m}$ PVDF membranes and probed with the selected antibodies in DecaProbe chambers (PR 150, Hoefer-GE, Barcelona, Spain). The primary antibodies were detected using the corresponding secondary antibodies and visualized by ECL (RPN2132, Amersham Biosciences).

\section{Bimolecular fluorescence complementation analysis}

The pPD49.83 plasmid was used to generate two cloning vectors for BiFC analysis (44). The constructs containing the N-terminal fragment of Venus truncated at residue 173 (VN173) or the C-terminal fragment of Venus starting at residue 155 (VC155) were a gift from Dr Chang-Deng $\mathrm{Hu}$ at Purdue University (USA). Chinese hamster ovary (CHO) cells were transfected using Lipofectamine 2000 (Invitrogen) and incubated for $24 \mathrm{~h}$ prior to testing for transgenic expression. Samples were visualized on glass bottom plates (MatTek Co, MA) using a Leica DMIII 6000 CS confocal fluorescence microscope equipped with a TCS SP5 scanning laser.

\section{Surface plasmon resonance analysis}

Interactions were determined using a BIACORE X (GE) as described previously (43). The GPCRs $(50 \mu \mathrm{g} / \mathrm{mL})$ were coupled to a CM5 sensor chip (GE, BR-1000-14) by amine coupling, and sensorgrams were collected at $25^{\circ} \mathrm{C}$ at a flow rate of $5 \mu \mathrm{L} / \mathrm{min}$ after passing $\operatorname{RGSZ2}(75 \mu \mathrm{L})$ over the sensor surface. Increasing analyte concentrations were studied and the results were plotted using the BIAevaluation software (v 4.1).

\section{In vitro interaction between RGSZ2/PKC $\gamma$ and HINT1 proteins: The effects of zinc ions and PMA}

The interaction of recombinant HINT1 (200 nM) with either GST-RGSZ2 (100 nM) or GST-PKC $\gamma$ (100 nM; Abnova \#P4759) was studied. Zinc was first removed from the recombinant proteins by incubating them for $60 \mathrm{~min}$ at room temperature (RT) in a buffer containing $10 \mathrm{mM}$ HEPES (pH 7.5), $150 \mathrm{mM}$ $\mathrm{NaCl}, 5 \mathrm{mM}$ EDTA, $200 \mu M$ DTT, and $1 \mathrm{mM} \mathrm{N}, \mathrm{N}, \mathrm{N}^{\prime}, \mathrm{N}^{\prime}$-tetrakis(2-pyridylmethyl) ethylenediamine (TPEN) (48). The samples were diluted in $10 \mathrm{mM}$ HEPES ( $\mathrm{pH} 7.5), 150 \mathrm{mM}$ $\mathrm{NaCl}$, and concentrated in centrifugal filter devices $(10 \mathrm{kDa}$ nominal molecular weight limit: Amicon Microcon YM-10 \#42407, Millipore). After zinc removal with TPEN, the influence of added zinc on the association of the recombinant proteins was evaluated by incubating them either alone (negative control) or together with the GST tagged protein in $400 \mu \mathrm{L}$ of a buffer containing $10 \mathrm{mM}$ HEPES (pH 7.4), $150 \mathrm{mM}$ $\mathrm{NaCl}$, and $0.05 \%$ Tween20. Recombinant HINT1 was incubated for $30 \mathrm{~min}$ with rotation at RT with GST-RGSZ2 or GSTPKC $\gamma$ in the presence of increasing amounts of zinc chloride: $1 \mathrm{p} M, 1 \mathrm{n} M$, and $1 \mu \mathrm{M}$ (Puratronic, Alfa Aesar 231-592-0). Subsequently, $40 \mu \mathrm{L}$ glutathione Sepharose 4B (GE\#17 0756 01) was added to the protein mixture, which was then recovered by centrifugation, washed three times, solubilized in 2X Laemmli buffer, and the presence of HINT1 was analyzed in Western blots. In another set of assays, endogenous zinc was first removed from the HINT1 and GST-PKC $\gamma$ proteins, and they were then incubated in the presence of $1 \mu \mathrm{M}$ zinc chloride for $30 \mathrm{~min}$ at RT before the free zinc was removed using $10 \mathrm{kDa}$ nominal molecular weight limit centrifugal filter devices (Amicon Microcon YM-10 \#42407, Millipore). Parallel samples were used to evaluate the disrupting effect of PMA (Calbiochem \#524400) on the PKC $\gamma /$ HINT1 association, as well as on the resulting enzymatic activity of this PKC $\gamma$. The latter was determined using the Pep Tag protein kinase $C$ assay (Promega, Madison, WI). Samples containing the HINT1/PKC $\gamma$ complexes that had been exposed to PMA were incubated for $30 \mathrm{~min}$ at $30^{\circ} \mathrm{C}$ with the specific substrate in the presence of an activating solution. The reaction was stopped at $95^{\circ} \mathrm{C}$ for $10 \mathrm{~min}$ and the $\mathrm{PKC} \gamma$-induced phosphorylation of the peptide substrate was determined.

\section{In vitro effect of zinc ions on the recruitment of signaling proteins to GPCRs: Influence of zinc chelation and NO generators}

The effect of increasing concentrations of zinc on the association of PKC $\gamma$ and Raf- 1 with various GPCRs was studied in cortical synaptosomal membranes. Membranes were incubated with zinc chloride (Puratronic, Alfa Aesar 231-592-0) for $4 \mathrm{~h}$ at $4^{\circ} \mathrm{C}$ before the GPCRs were immunoprecipitated. Subsequently, free zinc ions were removed by centrifugation and extensive washing. The synaptosomal membranes were then solubilized in Nonidet P-40 buffer as described previously. The solubilized membranes were incubated overnight at $4^{\circ} \mathrm{C}$ with approximately $3 \mu \mathrm{g}$ of a biotin (Pierce \#21217 and 21339) 
conjugated primary antibody (affinity-purified IgGs) raised against extracellular sequences in 5HT1AR, 5HT2AR, CB1R, and D2R. The GPCR-associated proteins were then separated by SDS-PAGE and analyzed by Western blotting. The samples were incubated overnight at $4{ }^{\circ} \mathrm{C}$ with the NO generator SNAP (Tocris Bioscience \#0598) and the anti-GPCRs IgGs, and the procedure was continued as described above. The heavy metal ion chelator TPEN (Fluka WA16827) was added to the solubilized samples together with SNAP.

\section{Statistical analyses}

ANOVA, followed by the Student-Newman-Keuls test (SigmaStat, SPSS Science Software, Erkrath, Germany) was used for the statistical analyses. The significance was defined as $p<0.05$.

\section{Acknowledgments}

This research was supported by FIS PS09/00332 (JG), PI1101704 (PSB). We would like to thank Beatriz Fraile and Gabriela de Alba for their excellent technical assistance.

\section{Author Disclosure Statement}

The authors declare that, excluding income received from our primary employer "Ministerio de Ciencia e Innovación, e Instituto de Salud Carlos III" no financial support or compensation has been received from any individual or corporate entity over the past 3 years for research or professional services, and that there are no personal financial holdings that could be perceived as constituting a potential conflict of interest.

\section{References}

1. Ajit SK, Ramineni S, Edris W, Hunt RA, Hum WT, Hepler JR, and Young KH. RGSZ1 interacts with protein kinase C interacting protein PKCI-1 and modulates mu opioid receptor signaling. Cell Signal 19: 723-730, 2007.

2. Barbier E and Wang JB. Anti-depressant and anxiolytic like behaviors in PKCI/HINT1 knockout mice associated with elevated plasma corticosterone level. BMC Neurosci 10: 132, 2009.

3. Bokoch GM, Diebold B, Kim JS, and Gianni D. Emerging evidence for the importance of phosphorylation in the regulation of NADPH oxidases. Antioxid Redox Signal 11: 24292441, 2009.

4. Colvin RA, Holmes WR, Fontaine CP, and Maret W. Cytosolic zinc buffering and muffling: Their role in intracellular zinc homeostasis. Metallomics 2: 306-317, 2010.

5. Cope EC and Levenson CW. Role of zinc in the development and treatment of mood disorders. Curr Opin Clin Nutr Metab Care 13: 685-689, 2010.

6. Csermely P, Szamel M, Resch K, and Somogyi J. Zinc can increase the activity of protein kinase $C$ and contributes to its binding to plasma membranes in T lymphocytes. J Biol Chem 263: 6487-6490, 1988.

7. Csermely P, Szamel M, Resch K, and Somogyi J. Zinc increases the affinity of phorbol ester receptor in T lymphocytes. Biochem Biophys Res Commun 154: 578-583, 1988.

8. Doyle T, Bryant L, Muscoli C, Cuzzocrea S, Esposito E, Chen $\mathrm{Z}$, and Salvemini D. Spinal NADPH oxidase is a source of superoxide in the development of morphine-induced hy- peralgesia and antinociceptive tolerance. Neurosci Lett 483: 85-89, 2010.

9. Garcia DE, Brown S, Hille B, and Mackie K. Protein kinase C disrupts cannabinoid actions by phosphorylation of the CB1 cannabinoid receptor. J Neurosci 18: 2834-2841, 1998.

10. Garzón J, de la Torre-Madrid E, Rodríguez-Muñoz M, Vicente-Sánchez A, and Sánchez-Blázquez P. Gz mediates the long-lasting desensitization of brain CB1 receptors and is essential for cross-tolerance with morphine. Molecular Pain 5: $11,2009$.

11. Garzón J, Rodríguez-Muñoz M, López-Fando A, and Sánchez-Blázquez P. The RGSZ2 protein exists in a complex with mu-opioid receptors and regulates the desensitizing capacity of Gz proteins. Neuropsychopharmacology 30: 16321648, 2005.

12. Garzón J, Rodríguez-Muñoz M, and Sánchez-Blázquez P. Morphine alters the selective association between mu-opioid receptors and specific RGS proteins in mouse periaqueductal gray matter. Neuropharmacology 48: 853-868, 2005.

13. Garzón J, Rodriguez-Muñoz M, and Sánchez-Blázquez P. Do pharmacological approaches that prevent opioid tolerance target different elements in the same regulatory machinery? Curr Drug Abuse Rev 1: 222-238, 2008.

14. Garzón J, Rodríguez-Muñoz M, Vicente-Sánchez A, Bailón C, Martínez-Murillo R, and Sánchez-Blázquez P. RGSZ2 binds to the neural nitric oxide synthase PDZ domain to regulate mu-opioid receptor-mediated potentiation of the $\mathrm{N}$ methyl-D-aspartate receptor-calmodulin-dependent protein kinase II pathway. Antioxid Redox Signal 15: 873-887, 2011.

15. Garzón J, Rodríguez-Muñoz M, Vicente-Sánchez A, GarcíaLópez MA, Martínez-Murillo R, Fischer T, and SánchezBlázquez P. SUMO-SIM interactions regulate the activity of RGSZ2 proteins. PLoS One 6: e28557, 2011.

16. Grabrucker AM, Rowan M, and Garner CC. Brain-delivery of zinc-ions as potential treatment for neurological diseases: Mini review. Drug Deliv Lett 1: 13-23, 2011.

17. Grabrucker AM, Schmeisser MJ, Udvardi PT, Arons M, Schoen M, Woodling NS, Andreasson KI, Hof PR, Buxbaum JD, Garner CC, and Boeckers TM. Amyloid beta proteininduced zinc sequestration leads to synaptic loss via dysregulation of the ProSAP2/Shank3 scaffold. Mol Neurodegener 6: 65, 2011.

18. Guang W, Wang H, Su T, Weinstein IB, and Wang JB. Role of $\mathrm{mPKCI}$, a novel mu-opioid receptor interactive protein, in receptor desensitization, phosphorylation, and morphineinduced analgesia. Mol Pharmacol 66: 1285-1292, 2004.

19. Hoyos B, Imam A, Chua R, Swenson C, Tong GX, Levi E, Noy $\mathrm{N}$, and Hammerling $\mathrm{U}$. The cysteine-rich regions of the regulatory domains of Raf and protein kinase $C$ as retinoid receptors. IExp Med 192: 835-845, 2000.

20. Ilbert M, Graf PC, and Jakob U. Zinc center as redox switch-New function for an old motif. Antioxid Redox Signal 8: 835-846, 2006.

21. Jordan JD, Carey KD, Stork PJ, and Iyengar R. Modulation of rap activity by direct interaction of Galpha(o) with Rap1 GTPase-activating protein. I Biol Chem 274: 21507-21510, 1999.

22. Knapp LT and Klann E. Superoxide-induced stimulation of protein kinase $C$ via thiol modification and modulation of zinc content. I Biol Chem 275: 24136-24145, 2000.

23. Korichneva I. Zinc dynamics in the myocardial redox signaling network. Antioxid Redox Signal 8: 1707-1721, 2006.

24. Korichneva I, Hoyos B, Chua R, Levi E, and Hammerling U. Zinc release from protein kinase $C$ as the common event 
during activation by lipid second messenger or reactive oxygen. L Biol Chem 277: 44327-44331, 2002.

25. Lima CD, Klein MG, Weinstein IB, and Hendrickson WA. Three-dimensional structure of human protein kinase $C$ interacting protein 1, a member of the HIT family of proteins. Proc Natl Acad Sci USA 93: 5357-5362, 1996.

26. Lindholm E, Ekholm B, Shaw S, Jalonen P, Johansson G, Pettersson U, Sherrington R, Adolfsson R, and Jazin E. A schizophrenia-susceptibility locus at $6 \mathrm{q} 25$, in one of the world's largest reported pedigrees. Am J Hum Genet 69: 96105, 2001.

27. Lipton SA. Paradigm shift in neuroprotection by NMDA receptor blockade: Memantine and beyond. Nat Rev Drug Discov 5: 160-170, 2006.

28. Liu Q, Puche AC, and Wang JB. Distribution and expression of protein kinase $C$ interactive protein (PKCI/HINT1) in mouse central nervous system (CNS). Neurochem Res 33: 1263-1276, 2008.

29. Maeng $S$ and Zarate Jr CA. The role of glutamate in mood disorders: Results from the ketamine in major depression study and the presumed cellular mechanism underlying its antidepressant effects. Curr Psychiatry Rep 9: 467-474, 2007.

30. Mao H, Zhao Q, Daigle M, Ghahremani MH, Chidiac $P$, and Albert PR. RGS17/RGSZ2, a novel regulator of Gi/o, Gz, and Gq signaling. I Biol Chem 279: 26314-26322, 2004.

31. Maret W. The function of zinc metallothionein: A link between cellular zinc and redox state. $[$ Nutr 130: 1455S-1458S, 2000.

32. Maret W. Zinc coordination environments in proteins as redox sensors and signal transducers. Antioxid Redox Signal 8: 1419-1441, 2006.

33. Maret $\mathrm{W}$ and Vallee BL. Thiolate ligands in metallothionein confer redox activity on zinc clusters. Proc Natl Acad Sci USA 95: 3478-3482, 1998.

34. Marino SM and Gladyshev VN. Redox biology: Computational approaches to the investigation of functional cysteine residues. Antioxid Redox Signal 15: 135-146, 2011.

35. McDonald JR, Groschel-Stewart U, and Walsh MP. Properties and distribution of the protein inhibitor $(\mathrm{Mr} \mathrm{17,000)}$ of protein kinase C. Biochem J 242: 695-705, 1987.

36. Mechri A, Saoud M, Khiari G, d'Amato T, Dalery J, and Gaha L. Glutaminergic hypothesis of schizophrenia: Clinical research studies with ketamine. Encephale 27: 53-59, 2001.

37. Mocchegiani E, Bertoni-Freddari C, Marcellini F, and Malavolta $\mathrm{M}$. Brain, aging and neurodegeneration: Role of zinc ion availability. Prog Neurobiol 75: 367-390, 2005.

38. Nowak G, Szewczyk B, and Pilc A. Zinc and depression. An update. Pharmacol Rep 57: 713-718, 2005.

39. Palumaa P. Biological redox switches. Antioxid Redox Signal 11: 981-983, 2009.

40. Parker PJ, Coussens L, Totty N, Rhee L, Young S, Chen E, Stabel S, Waterfield MD, and Ullrich A. The complete primary structure of protein kinase $\mathrm{C}$-The major phorbol ester receptor. Science 233: 853-859, 1986.

41. Patel HH and Insel PA. Lipid rafts and caveolae and their role in compartmentation of redox signaling. Antioxid Redox Signal 11: 1357-1372, 2009.

42. Rodríguez-Muñoz M, de la Torre-Madrid E, Sánchez-Blázquez P, and Garzón J. Morphine induces endocytosis of neuronal mu-opioid receptors through the sustained transfer of Galpha subunits to RGSZ2 proteins. Mol Pain 3: 19, 2007.

43. Rodríguez-Muñoz M, Sánchez-Blázquez $\mathrm{P}$, Vicente-Sánchez A, Bailón C, Martín-Aznar B, and Garzón J. The histidine triad nucleotide-binding protein 1 supports mu-opioid re- ceptor-glutamate NMDA receptor cross-regulation. $\underline{\text { Cell Mol }}$ Life Sci 68: 2933-2949, 2011.

44. Rodríguez-Muñoz M, Sánchez-Blázquez P, Vicente-Sánchez A, Berrocoso E, and Garzón J. The mu-opioid receptor and the NMDA receptor associate in PAG neurons: Implications in pain control. Neuropsychopharmacology 37: 338-349, 2012.

45. Rodríguez-Muñoz M, Torre-Madrid E, Sánchez-Blázquez $\mathrm{P}$, and Garzón J. NO-released zinc supports the simultaneous binding of Raf- 1 and PKCgamma cysteine-rich domains to HINT1 protein at the mu-opioid receptor. Antioxid Redox Signal 14: 2413-2425, 2011.

46. Rodríguez-Muñoz M, Torre-Madrid E, Sánchez-Blázquez P, Wang JB, and Garzón J. NMDAR-nNOS generated zinc recruits PKCgamma to the HINT1-RGS17 complex bound to the $\mathrm{C}$ terminus of Mu-opioid receptors. Cell Signal 20: 1855$1864,2008$.

47. Sánchez-Blázquez P, Rodríguez-Muñoz M, and Garzón J. Mu-opioid receptors transiently activate the Akt-nNOS pathway to produce sustained potentiation of PKC-mediated NMDAR-CaMKII signaling. PLoS One 5: e11278, 2010.

48. Schiavo G, Benfenati F, Poulain B, Rossetto O, Polverino de LP, DasGupta BR, and Montecucco C. Tetanus and botulinum-B neurotoxins block neurotransmitter release by proteolytic cleavage of synaptobrevin. Nature 359: 832-835, 1992.

49. Shahani $\mathrm{N}$ and Sawa A. Nitric oxide signaling and nitrosative stress in neurons: Role for S-nitrosylation. Antioxid Redox Signal 14: 1493-1504, 2011.

50. Zhao F, Ilbert M, Varadan R, Cremers CM, Hoyos B, AcinPerez R, Vinogradov V, Cowburn D, Jakob U, and Hammerling U. Are zinc-finger domains of protein kinase $C$ dynamic structures that unfold by lipid or redox activation? Antioxid Redox Signal 14: 757-766, 2011.

Address correspondence to: Prof. Javier Garzón Instituto Cajal

Consejo Superior de Investigaciones Científicas (CSIC) Doctor Arce 37, 28002 Madrid Spain

E-mail: jgarzon@cajal.csic.es

Date of first submission to ARS Central, January 11, 2012; date of final revised submission, May 4, 2012; date of acceptance, May 6, 2012.

$\begin{aligned} & \quad \text { Abbreviations Used } \\ & 5 \mathrm{HT} 1 \mathrm{AR}=\text { serotonin receptor } 5 \mathrm{HT} 1 \mathrm{~A} \\ & 5 \mathrm{HT} 2 \mathrm{AR}=\text { serotonin receptor } 5 \mathrm{HT} 2 \mathrm{~A} \\ & \alpha 2 \mathrm{AR}=\text { adrenergic receptor } \alpha 2 \mathrm{~A} \\ & \mathrm{BiFC}=\text { bimolecular fluorescence complementation } \\ & \mathrm{CB} 1 \mathrm{R}=\text { cannabinoid receptor } 1 \\ & \mathrm{CRD}=\text { cysteine-rich domain } \\ & \mathrm{D} 1 \mathrm{R}=\text { dopamine receptor } 1 \\ & \mathrm{D} 2 \mathrm{R}=\text { dopamine receptor } 2 \\ & \mathrm{DAG}=\text { diacylglycerol } \\ & \mathrm{DOR}=\text { delta opioid receptor } \\ & \mathrm{GPCR}=\mathrm{G} \text { protein-coupled receptor } \\ & \mathrm{HINT} 1=\text { histidine triad nucleotide-binding protein } 1 \\ & \mathrm{~L}-\mathrm{NNA}=\text { NG-nitro-L-arginine }\end{aligned}$




\begin{tabular}{rl|} 
& Abbreviations Used (Cont.) \\
$\mathrm{M} 2 \mathrm{R}=$ & acetylcholine muscarinic receptor $\mathrm{M} 2$ \\
$\mathrm{M} 4 \mathrm{R}=$ & acetylcholine muscarinic receptor $\mathrm{M} 4$ \\
$\mathrm{mGlu} 2 \mathrm{R}=$ & glutamate metabotropic receptor 2 \\
$\mathrm{mGlu} 5 \mathrm{R}=$ & glutamate metabotropic receptor 5 \\
$\mathrm{MOR}=$ & mu opioid receptor \\
$\mathrm{NMDAR}=$ & $N$-methyl-D-aspartate receptor \\
$\mathrm{nNOS}=$ & neural nitric oxide synthase \\
$\mathrm{NO}=$ & nitric oxide \\
$\mathrm{NOR}-3=$ & $( \pm)-($ E)-ethyl-2-[(E)-hydroxyimino]-5-nitro- \\
& 3-hexeneamide
\end{tabular}

$\mathrm{PDZ}=$ protein motif [post synaptic density protein (PSD95), Drosophila disc large tumor suppressor (DlgA), and zona occludens-1 protein (zo-1)]

$\mathrm{PKC}=$ protein kinase $\mathrm{C}$

PLC $=$ phospholipase $C$

$\mathrm{PMA}=$ phorbol 12-myristate 13-acetate

$\mathrm{RGSZ2}=$ regulator of $\mathrm{G}$ protein signaling $\mathrm{Z} 2$

ROS $=$ reactive oxygen species

$\mathrm{SNAP}=(\mathrm{S})$-nitroso- $N$-acetylpenicillamine

TPEN $=N, N, N^{\prime}, N^{\prime}$-tetrakis(2-pyridylmethyl) ethylenediamine 